\title{
High-Rising Epiglottis in Children: Should It Cause Concern?
}

\author{
Nadeem Petkar, MBBS, MS, Christos Georgalas, MBBS, and \\ Abir Bhattacharyya, MBBS, MS
}

An omega-shaped epiglottis is frequently associated with laryngomalacia. However, an elongated highrising epiglottis can represent a normal variation of the larynx in a majority of pediatric patients. It is important to consider this in a healthy child with no complaints apart from the sensation of a foreign body in throat. This will avoid triggering any unnecessary investigation or treatment. An elongated epiglottis projecting in the oropharynx can appear as a foreign body and be a source of anxiety for the parents as well as the unaware family practitioner. We present such a case, with a brief discussion of the pediatric larynx and the omega-shaped epiglottis. (J Am Board Fam Med 2007;20:495-496.)

A 3-year-old girl was brought by her mother to the otolaryngology rapid access clinic. The girl had been complaining of an intermittent foreign body sensation in her throat. Her mother and the patient herself described a "googly" in the back of her throat when she popped her tongue out. There was no associated history of stridor, shortness of breath, or symptoms suggestive of a sleep apnea. There was no history of reflux disease or odynophagia.

During examination of the oral cavity, an anterior larynx was noted and an elongated high-rising epiglottis was clearly visible in the oropharynx (Figure 1). The tonsils were not inflamed and nasal examination was unremarkable. The extremely high-rising epiglottis was diagnosed as the cause of the foreign body sensation felt by the child. The child was not in respiratory distress and was maintaining good oxygen saturation on air. Both mother and child were reassured as to the benign nature of this condition and discharged.

This article was externally peer reviewed.

Submitted 13 December 2006; revised 24 January 2007; accepted 29 January 2007.

From Department of Otolaryngology-Head and Neck Surgery, Whipps Cross University, NHS Hospital NHS Trust, Leytonstone, London.

Funding: none.

Conflict of interest: none declared.

Corresponding author: Nadeem Petkar, Department of Otolaryngology and Head and Neck Surgery, Whipps Cross University Hospital, Whipps Cross Road, Leytonstone, London, E11 1NR, United Kingdom (E-mail: napetkar@yahoo.com).

\section{Discussion}

There are structural and functional differences between the pediatric and the adult larynx. The size of the larynx at birth is approximately one third the size of an adult larynx. It grows until the age of puberty, when it attains its final size. ${ }^{1}$ The supraglottic larynx makes an angle with the subglottis; the saccule varies and may be significantly larger (proportionately) than in an adult. In terms of position, the child's larynx is positioned higher in the neck, closer to the hyoid than in an adult. As part of a gradual process of descent, the larynx moves from the level of the second and third vertebrae (fetus) to the level of the fourth vertebrae (birth) to the fifth vertebrae at 6 years of age and to the level of the seventh vertebrae by puberty. As a result, the epiglottis projects into the oropharynx and is frequently visible.

Because the epiglottis is softer in a child than in an adult, its shape can vary considerably and can frequently assume an elongated, tubular shape and at times an omega shape. This shape of the epiglottis (with additional features of flaccidity and a tendency to collapse together with the aryepiglottic folds) is also seen in laryngomalacia. ${ }^{2}$ However, it is the tendency of supraglottic tissue to collapse, rather than the shape of the epiglottis that characterizes laryngomalacia; this results in the associated respiratory obstruction and sleep apnea.

Once a diagnosis of high-rising epiglottis has been made, patients and their parents simply need to be reassured as to the benign nature of this 


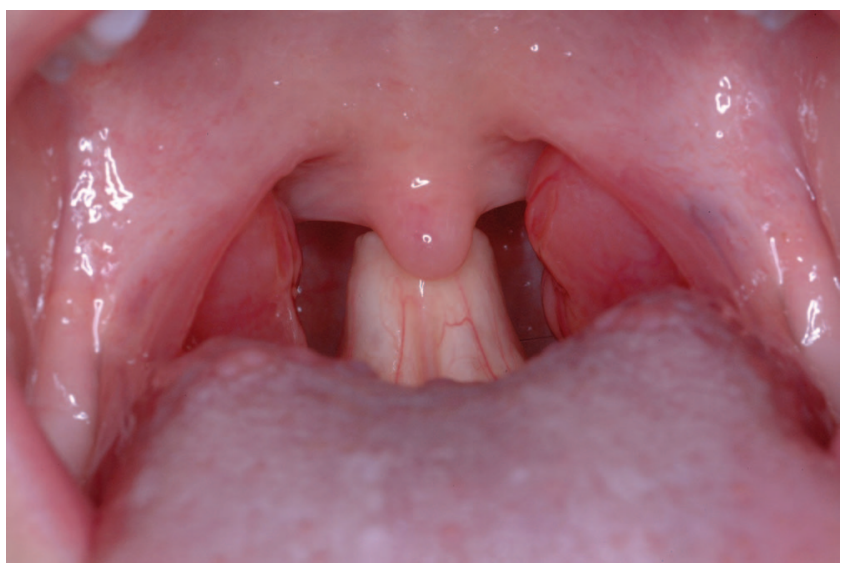

Figure 1. Oral cavity showing an extremely high-rising epiglottis behind the uvula.

condition, provided there are no signs of airway obstruction or sleep apnea. Patients may be referred to the otolaryngologist for confirmation of diagnosis, if required. For patients with respiratory compromise, especially those with severe laryngomalacia, surgical procedures like partial epiglottectomy, epiglottopexy, and recently epiglottoplasty have been described. Minor removal of the epiglottis does not interfere with phonation, respiration, or deglutition. However, we believe that in a majority of patients with only a high-rising epiglottis with no airway obstruction or other symptoms no further investigation or surgical intervention is required.

Rarer conditions associated with an omegashaped epiglottis include arthrogryposis multiplex congenital ${ }^{3}$ and the more recently described osteogenesis imperfecta. ${ }^{4}$ There are other congenital malformations of the epiglottis, which are also extremely rare. These include hypoplastic epiglottis, ${ }^{5}$ rudimentary epiglottis in syndromic children, ${ }^{6}$ and hemangiomas of the supraglottis. Bifid epiglottis is rare and presents as part of a syndrome such as Pallister-Hall syndrome ${ }^{7}$ (polydactyly, asymptomatic bifid epiglottis, and hypothalamic hamartoma) or Jouberts syndrome ${ }^{8}$ (hypotonia, ataxia, mental retardation, abnormal eye movements, and alternating tachypnea-apnea).

\section{Conclusion}

Children with elongated tubular epiglottis can present to the family physician with an intermittent foreign body sensation in throat of long duration.
The physician needs to be aware of a high-rising epiglottis to reassure patients and their parents. Otolaryngological consultation may be necessary to confirm the diagnosis. We must keep in mind that in the majority of pediatric patients with no symptoms of sleep apnea or upper airway obstruction, an elongated tubular epiglottis in a high positioned larynx is a normal variant of the pediatric larynx and should not in itself trigger any investigations or treatment.

\section{References}

1. Bruce B. Congenital disorders of the larynx. In: Cummings CW, Schuller DE, Krause CJ, editors. Paediatric otolaryngology-head and neck surgery, 3rd edition. St Louis, Baltimore: Mosby; 1998.

2. Prescott CA. The current status of corrective surgery for laryngomalacia. Am J Otolaryngol 1991;12:230-5.

3. Laureano AN, Rybak LP. Severe otolaryngologic manifestations of arthrogryposis multiplex congenital. Ann Otol Rhinol Laryngol 1990;99(2 Pt 1):94-7.

4. Li HY, Fang TJ, Lin JL, Lee ZL, Lee LA. Laryngomalacia causing sleep apnea in an osteogenesis imperfecta patient. Am J Otolaryngol 2002;23:37881 .

5. Benjamin B, Dalton C. Hypoplasia of the epiglottis: case report and review. Int J Pediatr Otorhinolaryngol 1996;38:65-9.

6. Li SP, Fang TJ, Lee SW, Li HY. A rudimentary epiglottis associated with Pierre Robin sequence. Int J Oral Maxillofac Surg 2006;35:668-70.

7. Stevens CA, Ledbetter JC. Significance of bifid epiglottis. Am J Med Genet A 2005;134:447-9.

8. Sung MW, Kim JW, Kim KH. Bifid epiglottis associated with Joubert's syndrome. Ann Otol Rhinol Laryngol 2001;110:194-6. 